\title{
Cultura Cultura
}

Revistade historia e Teria das ldeais $\quad$ Revista de História e Teoria das Ideias

vol. $21 \mid 2005$

Livro e Iconografia

\section{Paisagens sem rosto}

Para o estudo da primeira edição ilustrada de A Selva

Faceless landscapes

\section{Liliana Dias Carvalho}

\section{(2) OpenEdition}

Journals

\section{Edição electrónica}

URL: http://journals.openedition.org/cultura/3157

DOI: $10.4000 /$ cultura.3157

ISSN: 2183-2021

Editora

Centro de História da Cultura

\section{Edição impressa}

Data de publição: 1 Janeiro 2005

Paginação: 177-182

ISSN: 0870-4546

\section{Refêrencia eletrónica}

Liliana Dias Carvalho, « Paisagens sem rosto », Cultura [Online], vol. 21 | 2005, posto online no dia 15 março 2018, consultado a 03 maio 2019. URL : http://journals.openedition.org/cultura/3157 ; DOI : 10.4000/cultura.3157

Este documento foi criado de forma automática no dia 3 Maio 2019

(c) CHAM - Centro de Humanidades / Centre for the Humanities 


\title{
Paisagens sem rosto
}

\author{
Para o estudo da primeira edição ilustrada de A Selva
}

Faceless landscapes

Liliana Dias Carvalho

Este é um trecho das muitas cartas trocadas entre Ferreira de Castro e Roberto Nobre a propósito da edição ilustrada de A Selva, realizada em 1939 pela Empresa Nacional de Publicidade.

A edição, ilustrada por oito pintores contemporâneos, tinha como encomenda este tema genérico: De que modo os pintores portugueses vêm a Selva, depois de terem lido o romance de Ferreira de Castro. Roberto Nobre, coordenador gráfico da edição, incumbiu aos ilustradores - Alberto de Sousa, António Soares, Carlos Reis, Dórdio Gomes, Jorge Barradas, Manuel Lapa, Manuel Lima e Martins Barata -, que encontrassem o "rosto" da Selva, tal como Ferreira de Castro a descreve.

Esta encomenda passou por alguns sobressaltos, tendo sido necessário alterar o leque de ilustradores convidados, uma vez que parte do grupo inicial não conseguiu "agarrar" o romance. Os artistas revelaram alguma dificuldade em traduzir um cenário que desconheciam, não conseguindo sair do papel de intérpretes gráficos do romance. A situação em que foram colocados os pintores deriva da concepção que o encomendador e coordenador gráfico da edição - Roberto Nobre -, tem de ilustração. No Inquérito ao Livro em Portugal, coordenado por Irene Lisboa, Nobre defende que «em teoria, o ilustrador não deve ter personalidade própria e sim estar pronto a adaptar-se aos temas que surgem. (...) No nosso meio o ilustrador tem, em geral, uma personalidade muito vincada, cheia de carácter, o que muito o honra como artista, mas que lhe limita o campo de acção. 0 ilustrador é um intérprete e, como um executante em música, não deve sobrepor-se à obra de origem. $O$ artista português, em geral, não tem esse espírito de abdicação. Quase sempre (falo nos que têm talento e personalidade) é levado não a ilustrar, mas a ilustrarse, não a interpretar, mas a interpretar-se, não a prolongar apenas e com humildade junto do leitor a emoção colhida na leitura, mas impor uma versão sua, original e diferenciada. (...) o pintor e o escultor, quanto mais personalidade, quanto mais carácter e 
individualidade, melhor. 0 ilustrador, mesmo quando subjectivo, não pode esquecer-se de que é um intérprete.» ${ }^{2}$

Trazendo esta concepção de ilustração para o livro de Ferreira de Castro, surgem problemas prévios: se o livro remete para determinada paisagem, ou paisagens, como é que o ilustrador interpreta um território que, para si, é branco? Continuando, será possível estruturar picturalmente uma geografia imaginária sem ter uma memória afectiva do lugar ou, sem a possibilidade de ver a ilustração como algo que está para além de paráfrase do texto? Poderemos encarar o papel do ilustrador tal como Nobre o descreve? Se assim for, como classificar as ilustrações de Portinari para o mesmo romance, em 1955?

Recordemos que Nobre se referiu aos quadros do pintor brasileiro como tendo valor próprio como pintura, «em vez de usuais ilustrações». ${ }^{3}$ Para o coordenador da edição de 39, Portinari «não se aproveitou do mais fácil recurso decorativo da paisagem e antes se ocupou do que de humano se encontra naquele punhado de entes sofredores que a floresta tropical esmaga e tortura, mantendo-lhe o sentido estranho, o vigor, o carácter singular, que predominam e fizeram êxito na obra literária a que se destinam».4

O que Nobre não diz, mas podemos concluir das suas palavras, é que Portinari revela picturalmente um outro entendimento da ilustração e do papel do ilustrador. Vemos nas ilustrações de Portinari não paráfrases ou metonímias do livro de Castro, mas sim imagens que acompanham um texto, e que lhe servem de complemento coerente - não traduções pictóricas, até porque há a consciência de que, na "tradução", muita coisa se perderia e, uma delas seria evidentemente a identidade artística da ilustração e, lato sensu, do ilustrador. Acrescentamos aqui também que a edição ilustrada de 55, bem como a de 49 e de 74, de Machado da Luz e de Júlio Pomar, respectivamente, correspondem a um projecto relacional de um para um - um romance e um ilustrador -, ao passo que a edição de 39 tem uma relação de um romance para oito ilustradores. Arriscamos dizer que um projecto de edição de luxo, como foi esta, acabou por se tornar numa edição marginal. A Guimarães Editores só a refere em 1949 como sendo a 11", sem indicação de data.

No romance de Ferreira de Castro, o campo semântico da palavra selva é bastante abrangente: num sentido mais literal designa a floresta amazónica - um local geograficamente tipificado e delimitado -, mas é também uma ideia - uma entidade relacional -, e uma história sobre o Homem e os seus limites. A selva, diz-nos o narrador " dominava tudo. Não era o segundo reenvio, era o primeiro em força e categoria, tudo abandonando a um plano secundário. E o homem, simples transeunde no plano do enigma, via-se obrigado a entregar o seu destino àquele despotismo. 0 animal esfrangalhava-se no império vegetal e, para ter alguma voz na solidão reinante, forçoso se lhe tornava vestir pele de fera. A árvore solitária, que borda melancolicamente campos e regatos na Europa, perdia ali a sua graça e romântica sugestão e, surgindo em brenha inquietante, impunha-se como um inimigo. Dir-se-ia que a selva tinha, como os monstros fabulosos, mil olhos ameaçadores, que espiavam de todos os lados. Nada a assemelhava às últimas florestas do velho mundo, onde o espírito busca enlevo e o corpo frescura; assustava com o seu segredo, com o seu mistério flutuante e as suas eternas sombras, que davam às pernas nervoso anseio de fuga.» ${ }^{5}$ No romance de Castro, o nome selva torna-se atributo das coisas e dos seres em relação à paisagem envolvente. Portinari (1955) enten deu bem esta abertura de significados. 
Ora, seguindo a definição de ilustração que Nobre nos dá, será que uma obra aberta a tal multiplicidade, encontra uma boa tradução pictural em quadros fechados no tema floresta? Ou melhor, no tema floresta desconhecida pelos ilustradores?

Em 1795, François-René de Chateaubriand escreve a sua Lettre Sur le Paysage en Peinture. ${ }^{6}$ Neste texto, Chateaubriand critica o facto de, nos finais de século XVIII, a maioria dos paisagistas conhecerem pouco a paisagem que pintam e caracterizam. Por isso o autor alerta para a necessidade de os estudantes de pintura começarem a estudar verdadeiramente a natureza, saindo do atelier e observando os movimentos da paisagem. Sem um estudo baseado na experiência e na relação afectiva entre a memória do pintor e a paisagem não existe arte da paisagem - reproduzem-se tão somente traços da natureza que não têm a identidade própria de um lugar. Continuando com a lição de Cha teaubriand, se o pintor que se ocupa da natureza humana deve estudar as suas emoções para depois compreender as suas feições, o paisagista, tal como o poeta, só poderá ocupar-se da natureza se a estudar localmente, sabendo dela os seus cheiros, tonalidades e movimentos. Deste modo, o paisagista captará a influência dos diversos horizontes/ ambientes da tela que pinta.

A modernidade do texto de Chateaubriand advém justamente do facto de o autor não reivindicar uma memória empírica, mas sim uma memória afectiva, o que nos permite convocar o texto setecentista para este projecto de ilustração de A Selva, pois é essa a sua falha - a falta de uma memória afectiva (e aqui, temos de o dizer, também a inexistência de uma memória empírica). Abel Manta, um dos ilustradores convidados para a edição, desistiu dizendo que só indo à Amazónia conseguiria ilustrar o romance. Dos restantes quadros, temos a descrição que Nobre vai dando a Castro: «Meu caro Castro: V. deixou-me com uma bela herança. A Selva tem-me dado água pela barba. Em primeiro lugar os meus colegas. O Barradas apresenta-me uma floresta de pinheiros da Suécia, em tons suaves, estilo nevoeiro, tudo vago e pálido. Ele foi o primeiro a dizer-me que de facto aquilo não era a "Selva". Prometeu-me modificar. Mas até hoje não o arranjou. O Sousa Lopes não pode aceitar. O Abel Manta disse entusiasticamente que sim, tornou a ler o livro e convenceu-se que só indo lá é que conseguiria fazer alguma coisa. O Varela Aldemira tentou, não gostou do que fez e escreveu-me a dizer que o prazo era curto, tinha exames etc[.], o assunto difícil e que desistia. Enfim, isto é uma amostra.

(...) Julgo que $\mathrm{V}$. ficará contente com as vinhetas que tenho feito e que têm aqui agradado às pessoas a que tenho mostrado.

O quadro do António Soares é bonito como cor mas confuso.

o Dórdio Gomes mandou uma mancha forte, violenta que o Dr. Magnus acha o melhor do que tem visto sobre «A Selva». Não estou tão optimista mas julgo que depois de alguns retoques do "gravador" ficará bem. 0 resto tem sido uma dificuldade medonha. 0 Lino António deve entregar amanhã. Já está pronto. Os outros... vamos a ver quando se conseguirá arrancar-lhe [s] os trabalhos.» ${ }^{7}$

Noutra carta, continuando o relato da edição: «V. tem toda a razão para estranhar a minha falta de notícias.

Mas a publicação do seu livro tem sido uma tragédia tão grande que a falta de notícias ainda é para si um mal menor do que se $\mathrm{V}$. fosse posto dia a dia a corrente dos dissabores e arrelias que têm surgido!

(...) 
Posto aqui este desabafo vamos ao assunto: Depois das sete pragas do Egipto, são os pintores a pior praga que existe. Uma calamidade. Se V. soubesse o que apareceu entre as "selvas" pintadas! Dos meus convidados pessoais o Lino António parece que endoideceu. Tive que recusar os dois trabalhos que apresentou e, vendo que o segundo era ainda pior do que o primeiro, tive de desistir dele, pois deram-lhe explicações pormenorizadas do que se pretendia. Está a imitar o Mário Eloy e faz umas coisas que parecem uma palete borrada, não se entendendo nada daquelas pinceladas todas. Além de tudo o mais absolutamente feio e irritante. V. verá quando cá chegar. Para V. avaliar o que sofri com o Lino António basta dizer-lhe que para lhe arrancar aqueles dois trabalhos lhe telefonei dezoito vezes. Para não complicar a questão e de combinação com o Dr. Magnus resolvemos pagar-lhe e não publicar. O Guilherme Filipe disse-me que sim e levou mês e meio para responder sequer às minhas repetidas cartas. Tivemos que eliminá-lo.

Em substituição destes dois o Dr. Magnus deseja colocar jarrões da velha guarda com os amigos particulares dele Armando Lucena e... Alfredo Morais!

Ora eu estava ainda sob a terrível impressão do quadro de Carlos Reis... que até leões metia. Se algum daqueles fosse fazer os quadros, metia com certeza o jardim zoológico.

Preferi ir buscar novos, mesmo com nome menor. Escrevi a dois pintores da geração a seguir à nossa, de cujos trabalhos eu gostava. Um deles nem conhecia pessoalmente.

Falei-lhes em tom confidencial e incitei-lhes o brio. Consegui assim que um deles fizesse para mim o melhor quadro que vem no livro, o de Manuel Lapa. ${ }^{8}$ É um pintor de mérito. $O$ do outro pintor, Manuel Lima, não é tão bom, mas é cheio de cor e bonito. Está isto fora do nosso critério inicial, que era um ramalhete de nomes consagrados, mas, se V. cá estivesse teria feito outro tanto. Mesmo assim, V. verá o que Alberto de Sousa, Martins Barata e Carlos Reis mandaram! Este senhor é "tabu" para o Diário de Notícias. Por vontade minha teria corrido com ele. Ao menos o nome dele serve de cartaz. Mas ele pintou uma horta com um leão e uma serpente e supõe que isto é a "Selva"... leões no Brasil! Isto é que é cultura! Ao gravar, matamos-lhe o leão... O Dr. Magnus preferiu isto a recusar o trabalho de S. Majestade.

Isto é o drama pictural. O drama tipográfico ainda é mais longo. Fica para outra carta.»"

Com excertos destas duas cartas de 1938, temos o retrato dos primeiros ilustradores de $A$ Selva: duas gerações - sendo a dominante a que transita do século XIX para o século XX e tem Carlos Reis (1863-1940) como figura cimeira -, uma naturalista e outra ligada ao segundo Modernismo (em que se insere também Roberto Nobre) que não traduzem ou complementam a obra de Castro, criando cenas que não se identificam com o Naturalismo - pois são paisagens imaginadas, criadas em atelier - , nem com o Modernismo - uma vez que não conseguem criar um universo hipersinestésico, numa palavra, baudelaireano, onde todas as cores, sons e perfumes, tal como as artes, se correspondem.

As florestas pintadas pelos artistas portugueses são também destituídas de título. Um nome que poderia dar às ilustrações um rosto, um perfil de leitura pictural do romance, como acontece com as ilustrações de Portinari. E assim, temos umas florestas que não têm lugar no mundo, são de uma neutralidade que não encontra correspondência nas descrições que surgem no romance, tão cheias de vida. Para responder às questões que fomos enunciando, dizemos que a edição ilustrada de 1939 não cria uma relação de coerência relacional com o livro.

Entrando no domínio da pura conjectura, podemos dizer que, para o estudo desta edição ilustrada, seria proveitosa a existência de um outro contrato com estes ilustradores, 
formulado nestes termos: qual a ideia que os pintores portugueses têm de A Selva antes de lerem o livro de Castro e que transformação pictural conseguem operar depois da sua leitura. É claro que aqui entramos num registo quase ficcional, impossível de verificar com dados materiais. No entanto, permite-nos pensar se essas primeiras ilustrações, antes da leitura do romance, seriam muito diferentes daquelas que encontramos nesta edição...

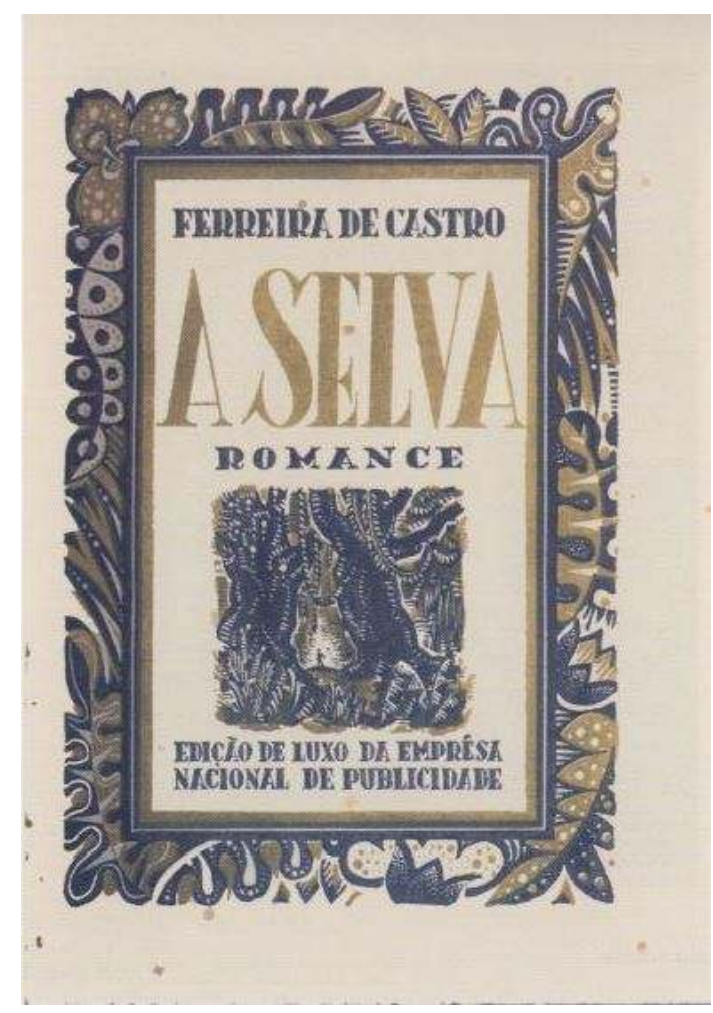

A SELVA, EDIçÃo dE 1939. 


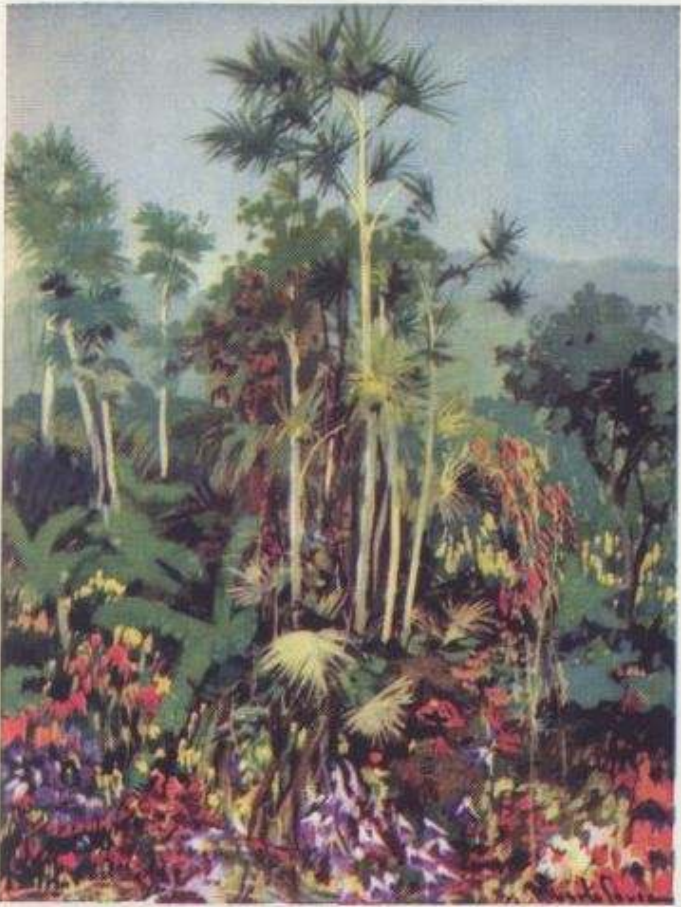

ALBERTO DE SOUSA.

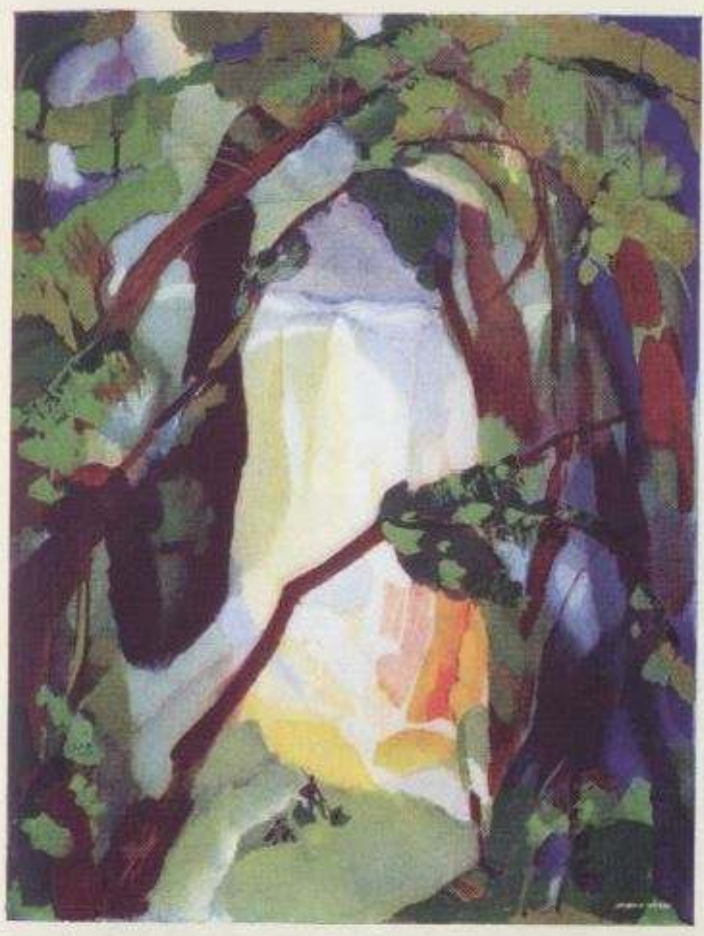

ANTÓNIO SOARES. 


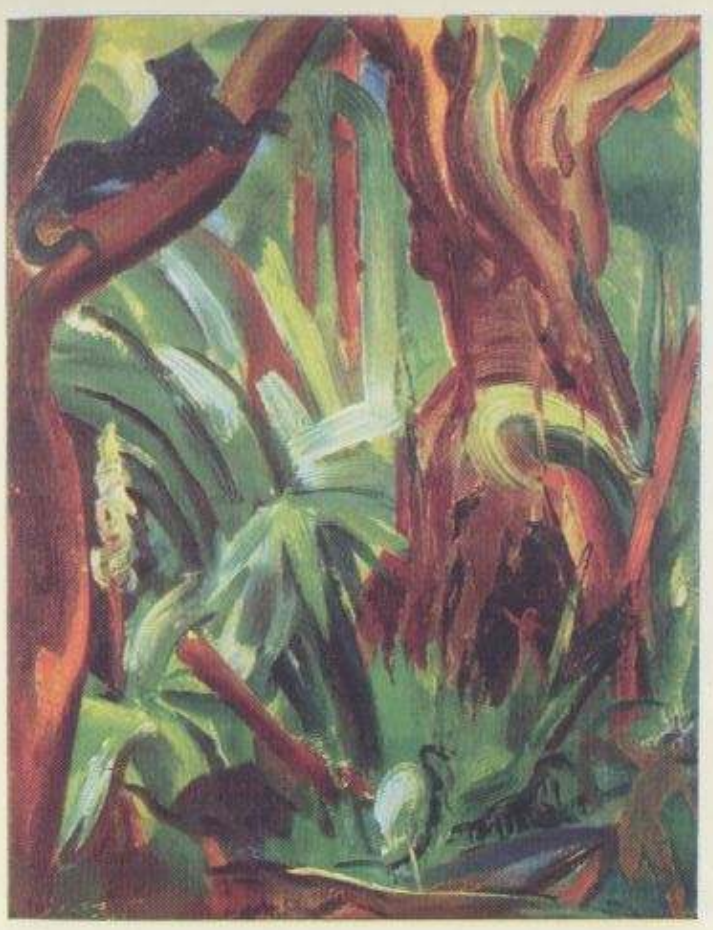

DÓRDIO GOMES.

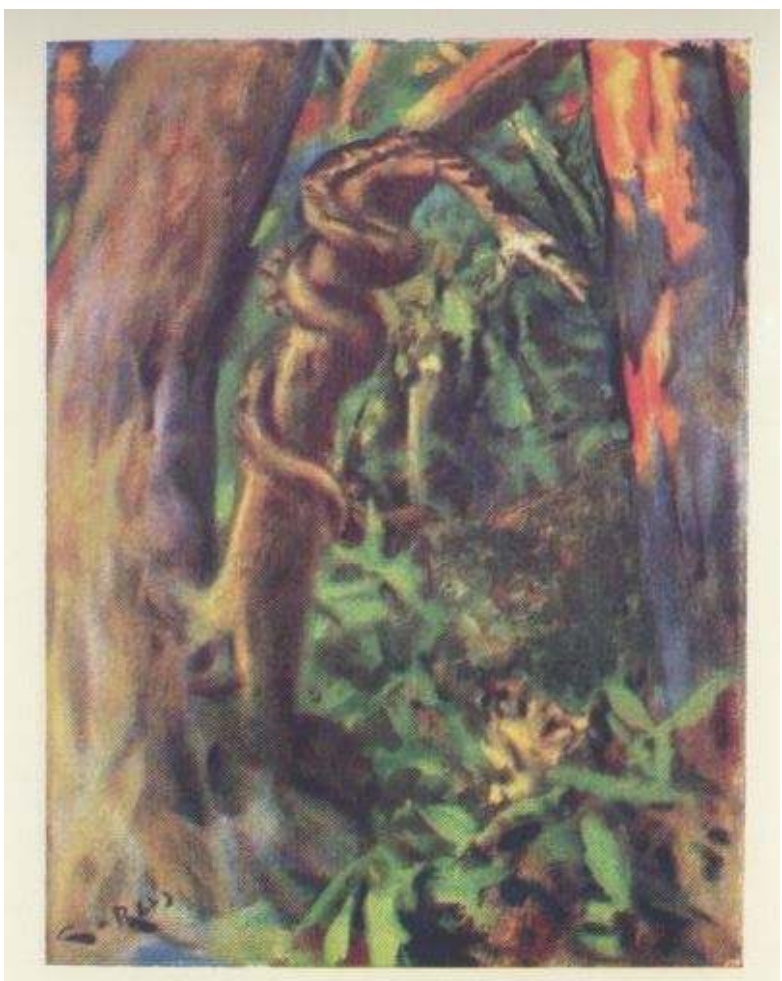

CARLos ReIS. 


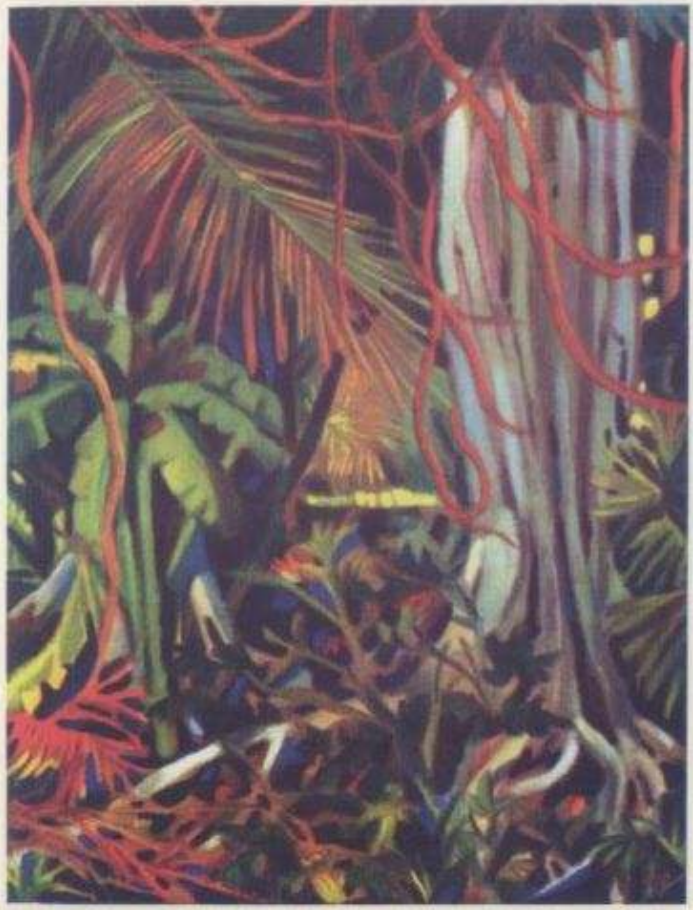

JORgE BARRADAS.

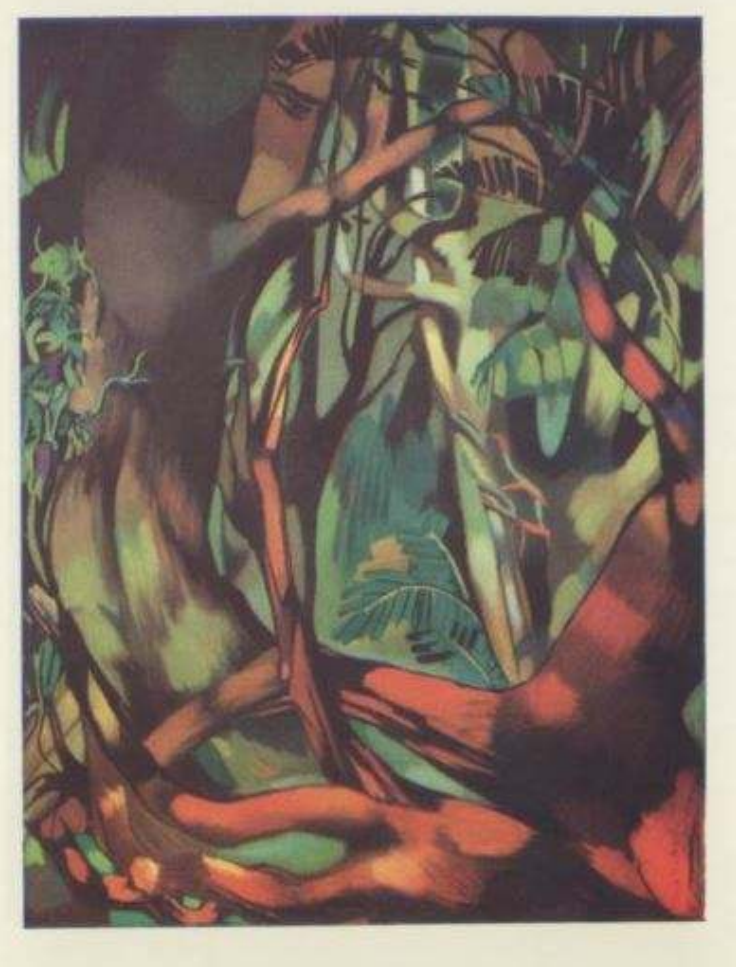

MANUEL LAPA. 


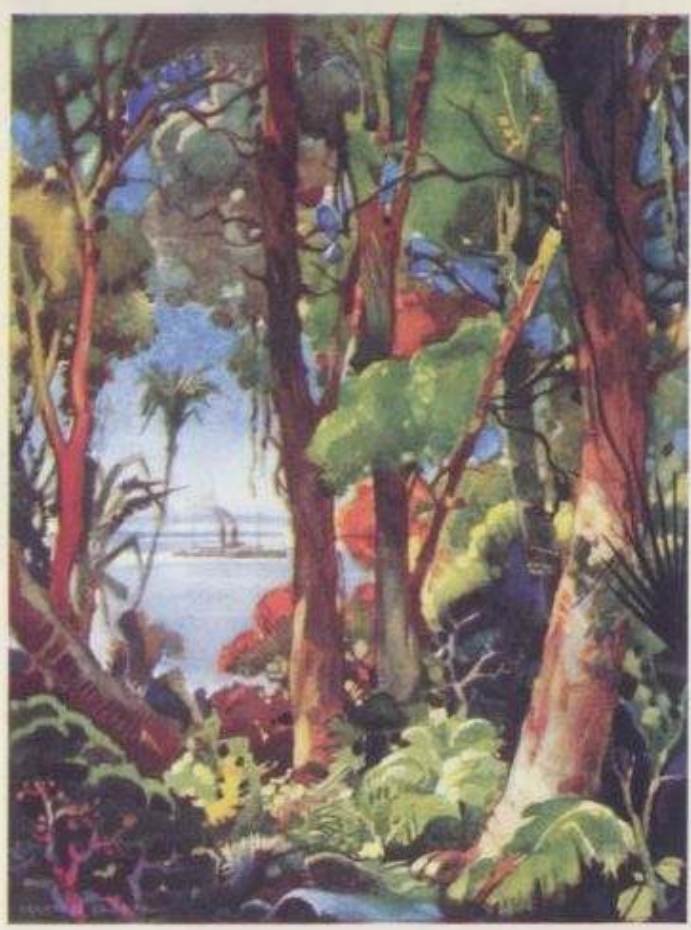

MARTINS BARATA.

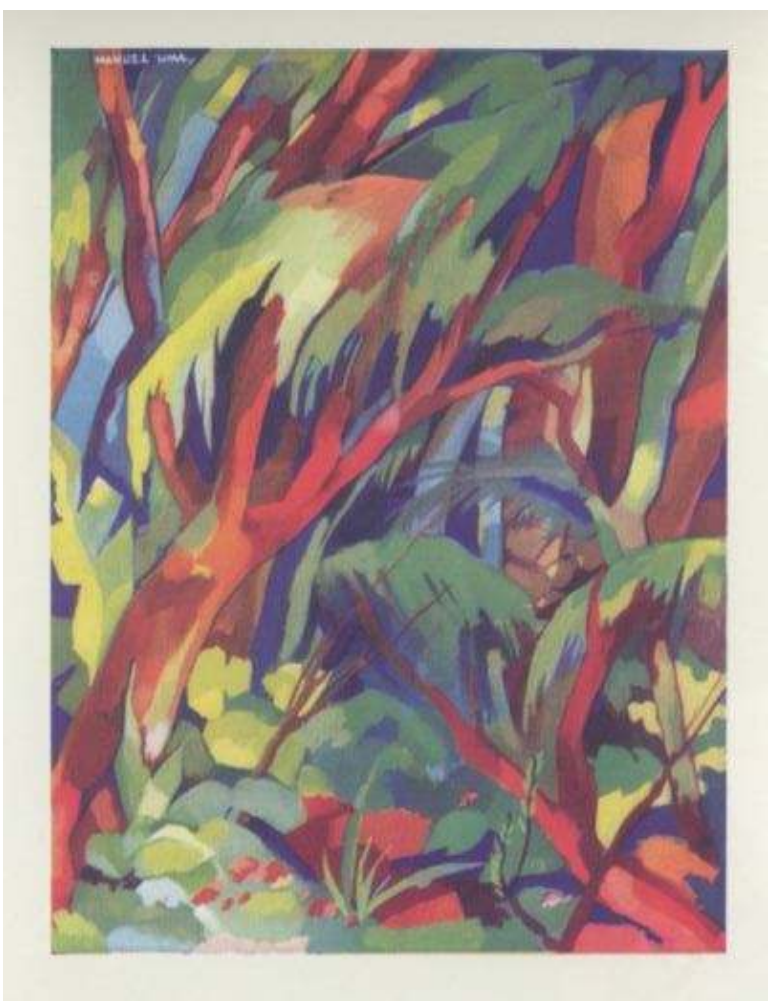

MANUEL LIMA. 
FERREIRA DE CASTRO

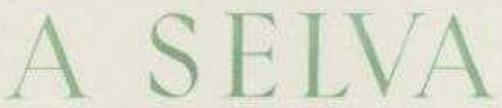

ILESTRAGOES DE PORTINARI

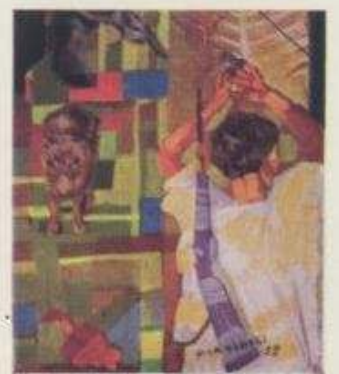

GUIMARAES EDITORES

A SELVA, EDIÇÃo DE 1955.

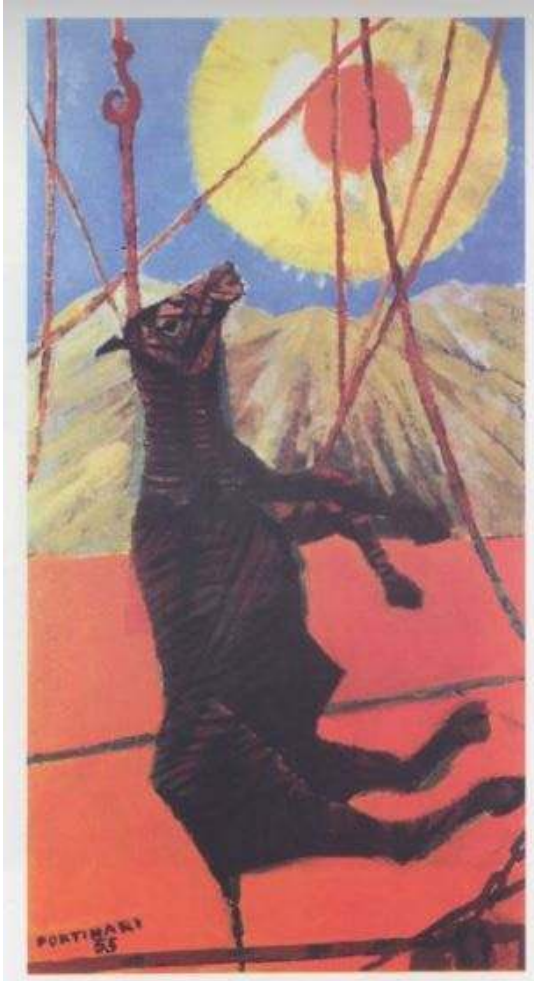

BOI NO GUINDASTE. 


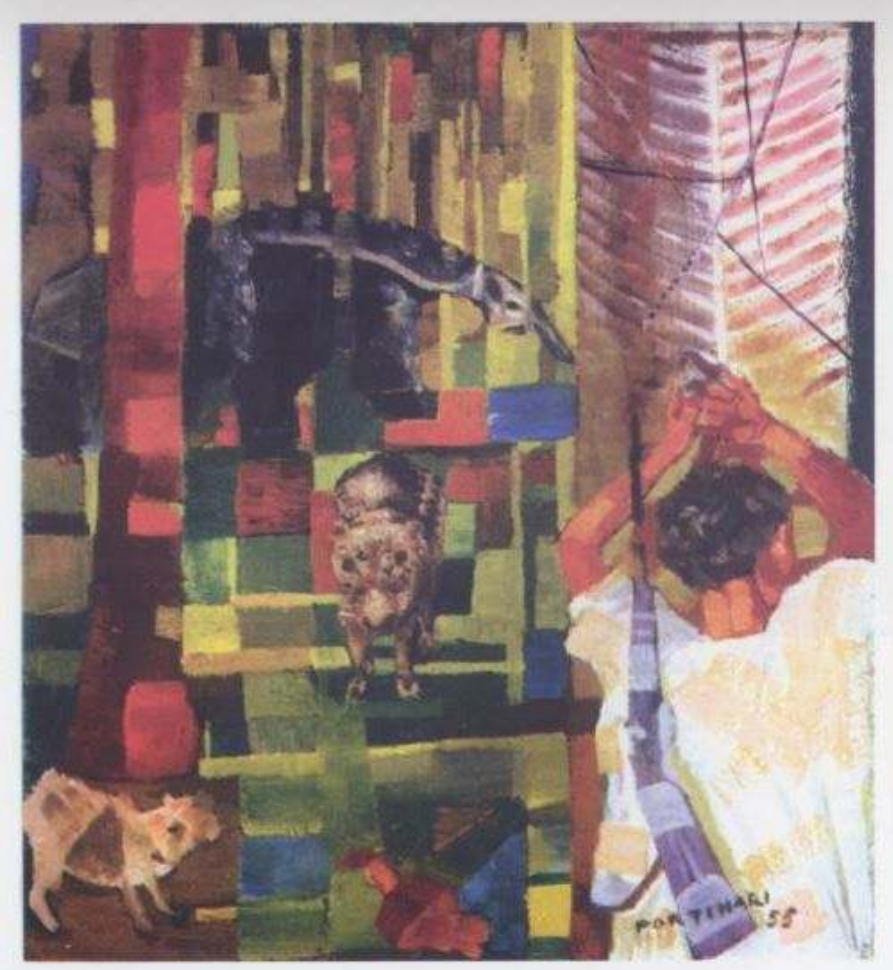

O SERINgUEIRO.

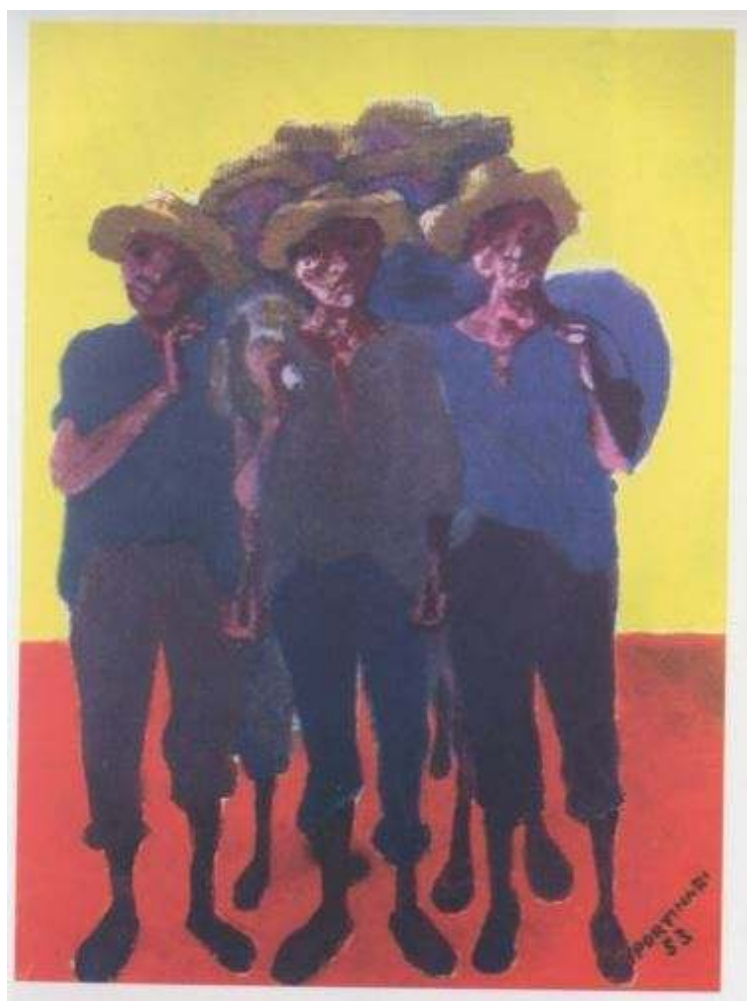

OS BRABOS. 


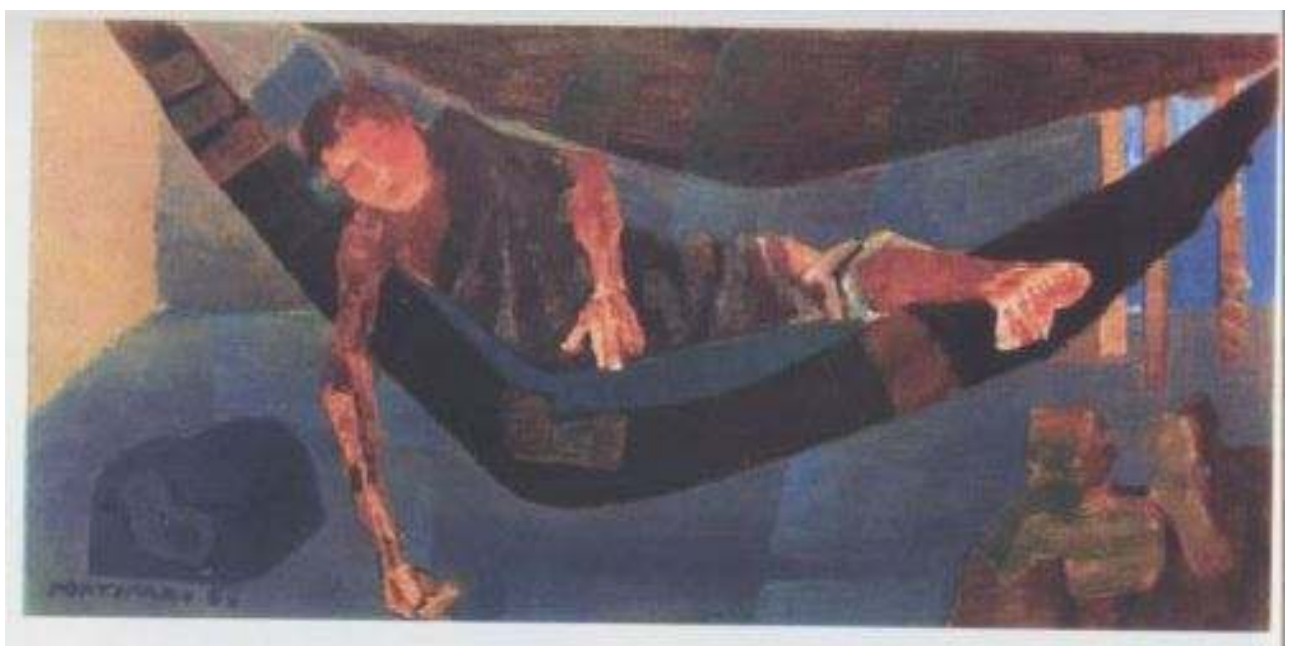

A REDE.

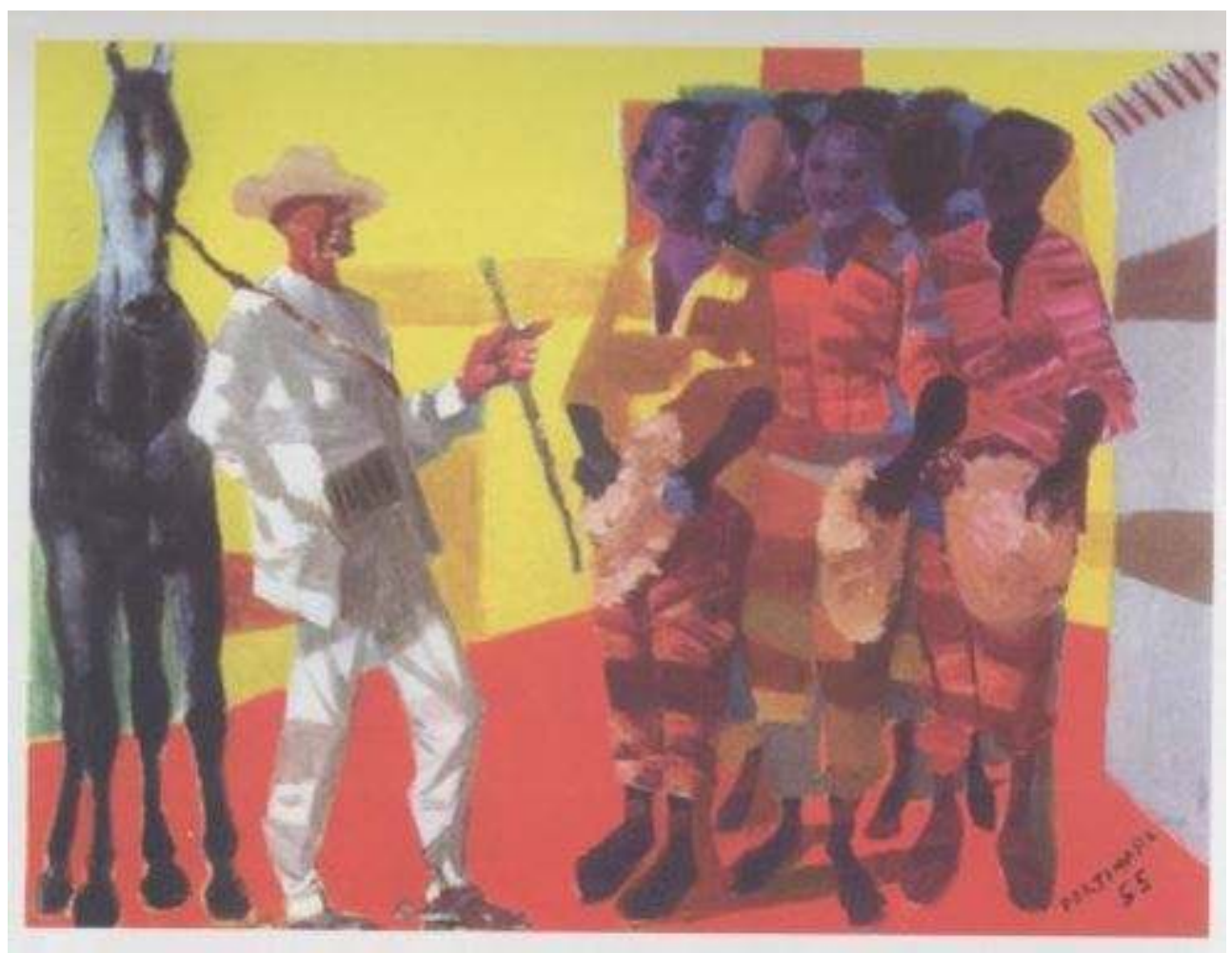

A INSPECÇÃo. 


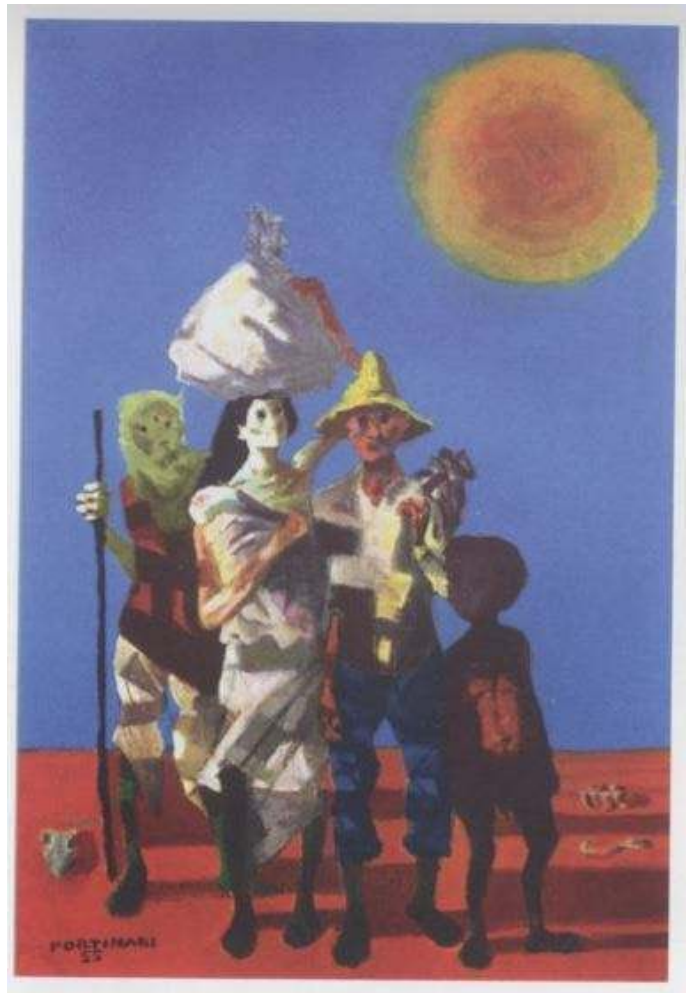

OS RETIRANTES.

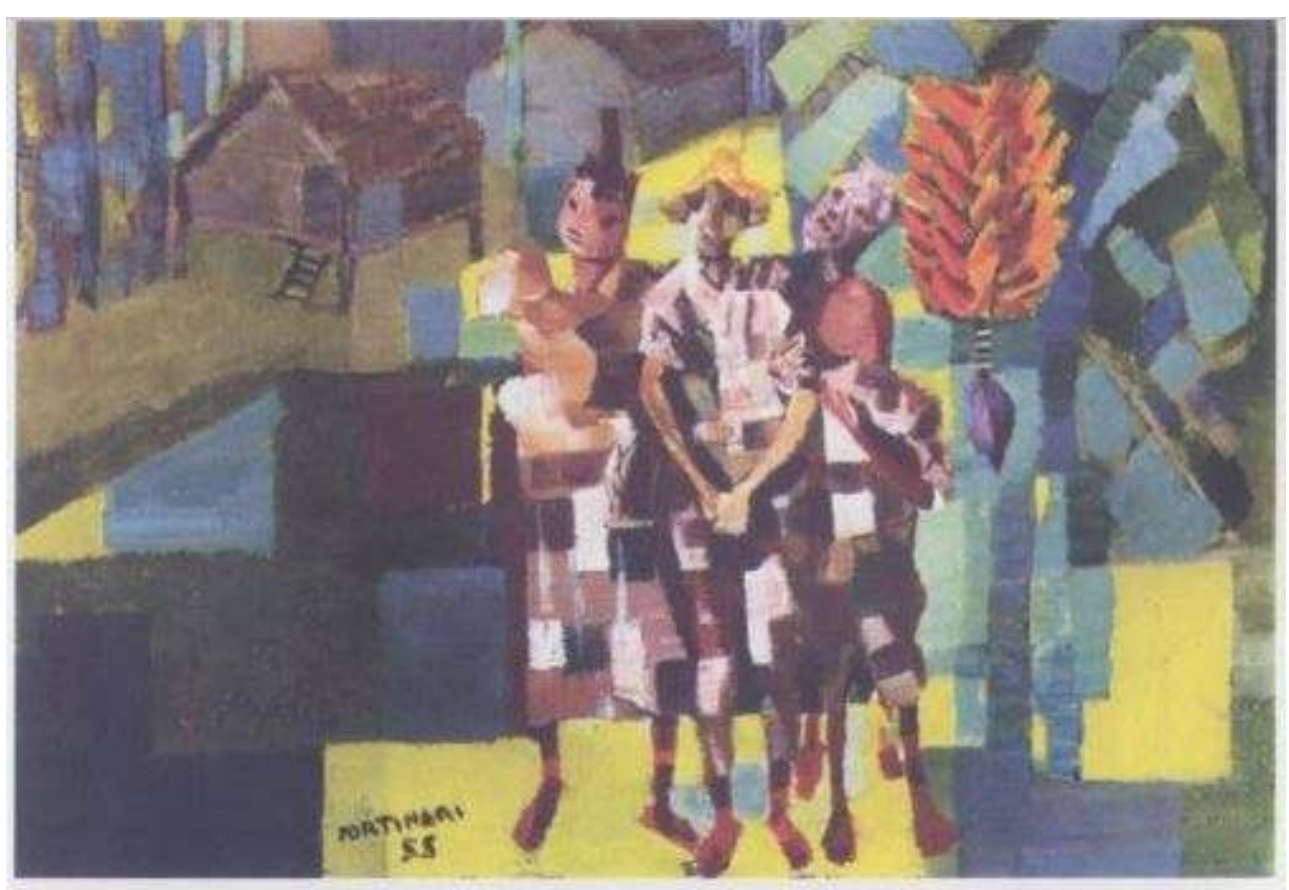

A Clareira. 


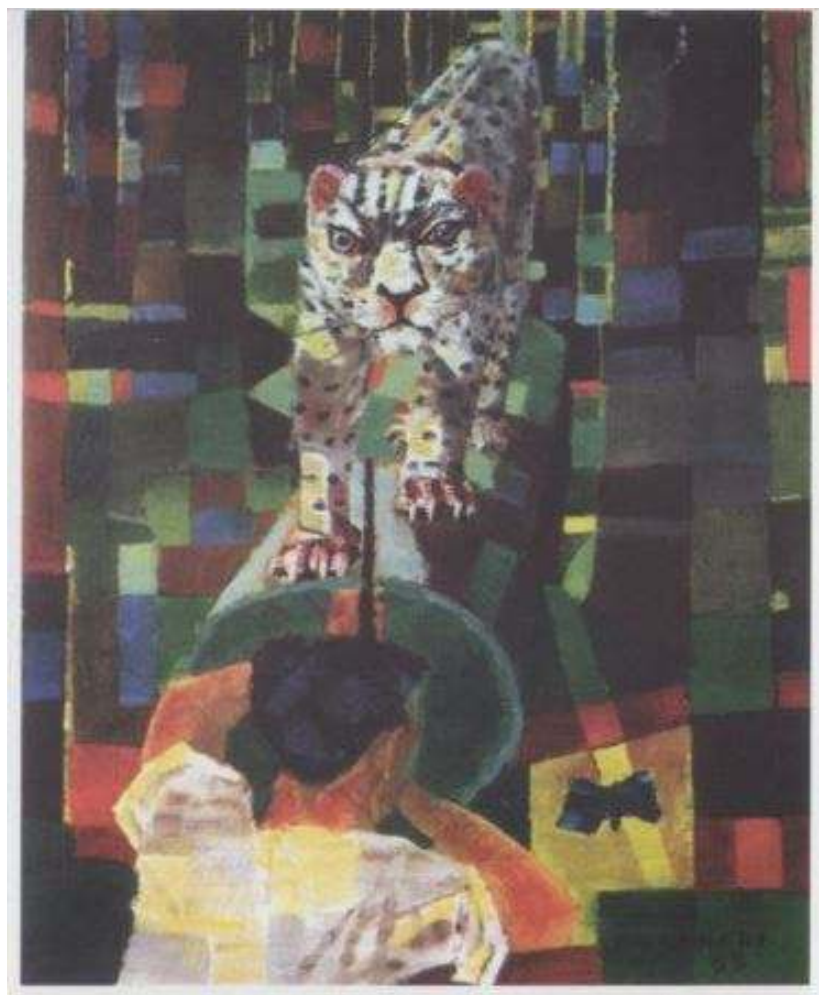

A ONÇA.

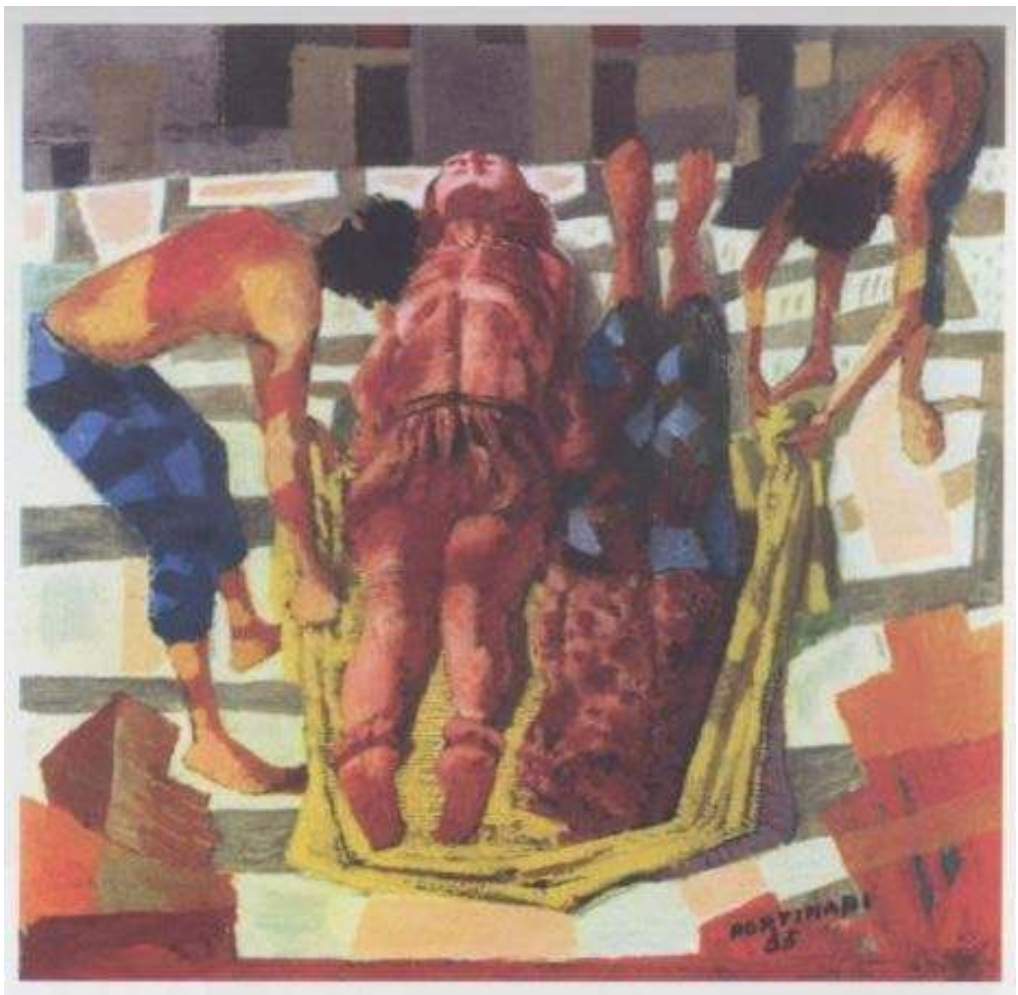

O ÍNDIO MORTO. 


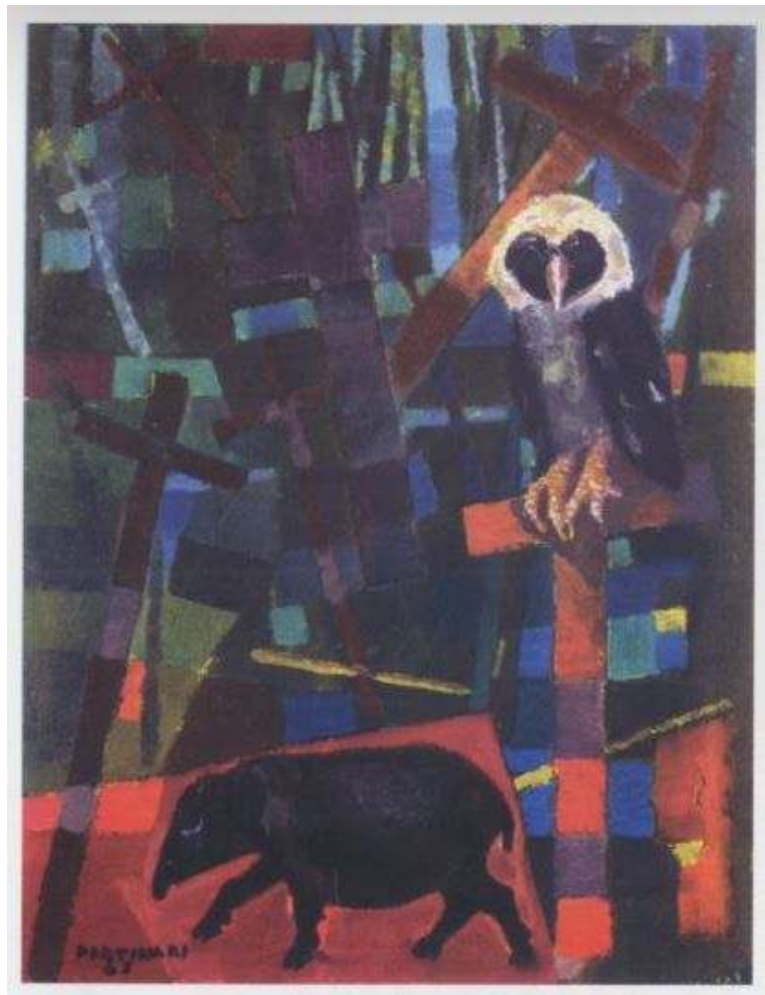

o Cemitério.

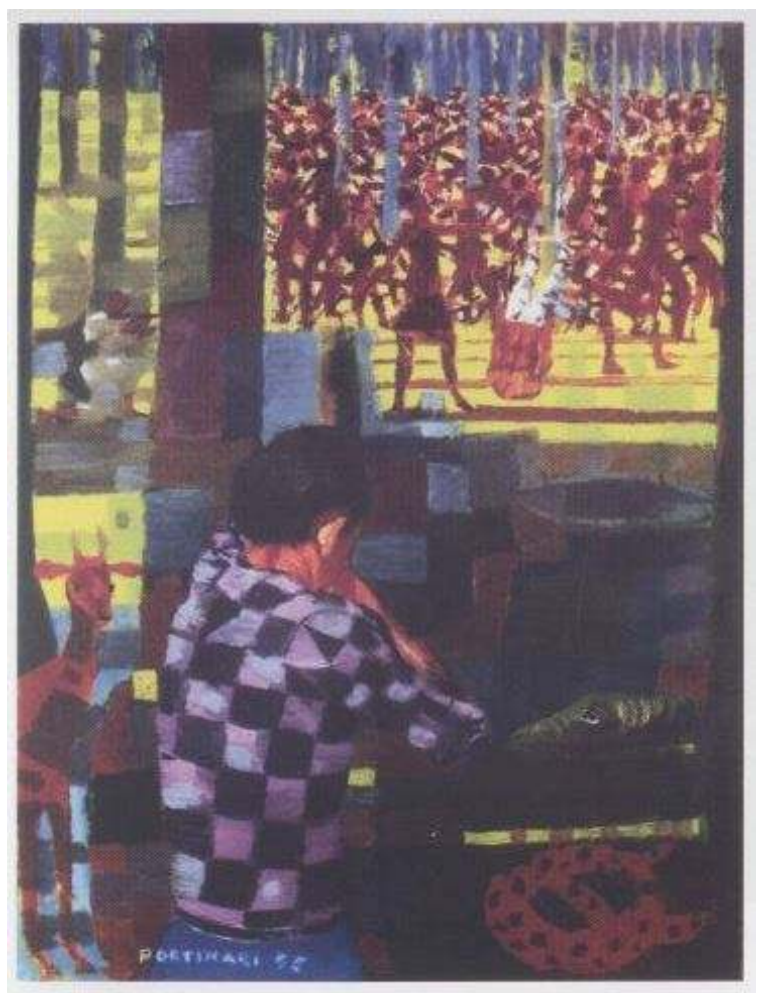

os ínDIos. 


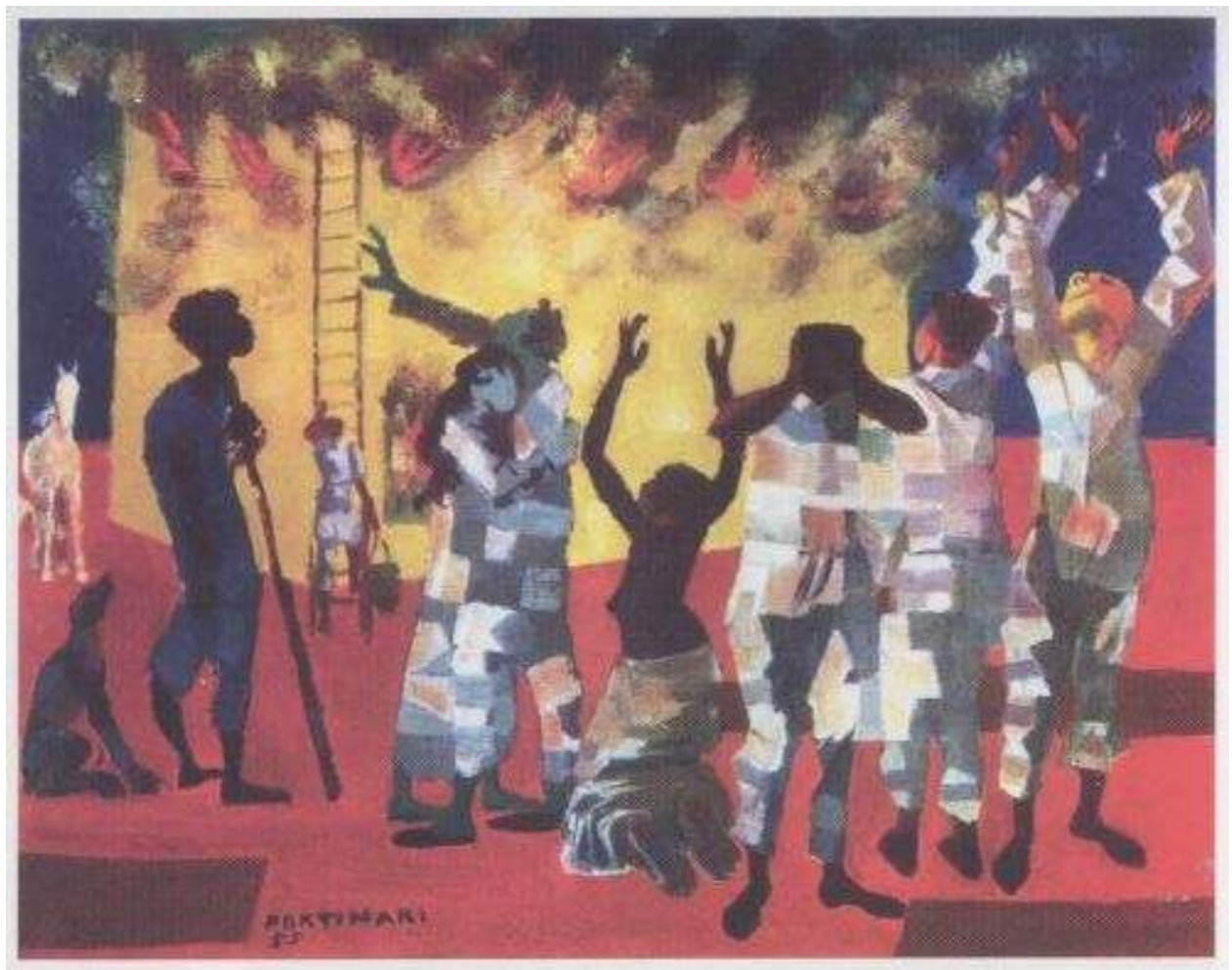

O INCÊNDIO.

\section{NOTAS}

2. Cf. "A Ilustração do Livro», Roberto Nobre In LISBOA, Irene (Dir.). Inquérito ao Livro em Portugal. Lisboa: Seara Nova. 1" Ed., 1946. PP. 74-80.

3. Cf. «A Exposição de Portinari» NOBRE, Roberto. In Ecos de O Primeiro de Janeiro, 18 de Maio de 1955.

4. Idem.

5. CASTRO, Ferreira de. A Selva. Lisboa: Ed. Guimarães, $39^{a}$ Edição, p. 88.

6. CHATEAUBRIAND, F.-R. Lettre Sur Le Paysage en Peinture. [1ª Ed., 1830] Ed. Ut.: Ed. Rumeur des Ages, 1993.

7. In ALVES, Ricardo António. Op. cit., pp. 64-65.

8. A ilustração preferida por Roberto Nobre denota um envolvimento do pintor pela pintura, como se a ilustração se transformasse em Floresta.

9. Idem, pp. 71-72. 


\section{RESUMOS}

O romance A Selva contou com quatro edições ilustradas: A de 1939, coordenada por Roberto Nobre, a de 1949, realizada por Machado da Luz, a de 1955, realizada por Cândido Portinari e uma última em 1974 realizada por Júlio Pomar. A primeira edição ilustrada correspondeu a um projecto de encomenda diferente das edições seguintes, nomeadamente da que serve aqui de termo de comparação, a de Portinari (1955). Roberto Nobre pretendia que oito ilustradores traduzissem picturalmente $A$ Selva a partir de uma geografia imaginária que o livro lhes desse a ver. Sendo a Selva um território estranho para os pintores desta edição, fica deste projecto uma tradução pela ilustração de paisagens sem identidade pictural - lugares brancos no conjunto das edições ilustradas do romance de Ferreira de Castro.

The novel A Selva has had four illustrations: being the first coordinated by Roberto Nobre (1939), the second by Machado da Luz (1974), the third by Cândido Portinari (1955) and the latest one by Júlio Pomar (1974). The first illustrated edition versed a different project from the further ones especially from the one which meant to be the comparison, the one by Portinari (1955). Roberto Nobre wanted eight illustrators to translate pictorially based on an imaginary geography pictured in the book. Although A Selva was an unknown ground for the painters of this same edition, there is a remarkable translation/understanding managed through the illustration of landscapes lacking pictorial identity - the very same vague places in the set of illustrated editions in Ferreira de Castro's novel.

\section{ÍNDICE}

Palavras-chave: Nobre, Roberto (1903-1969), Castro, Ferreira de (1898-1974), ilustração, Arte em Portugal no século XX, naturalismo, modernismo

Keywords: Nobre, Roberto (1903-1969), Castro, Ferreira de (1898-1974), illustration, Art on Portugal at XX Century, naturalism, modernism

\section{AUTOR}

\section{LILIANA DIAS CARVALHO}

Colégio Integrado Monte Maior (Montemor, Loures) Instituto de História da Arte - Núcleo de Estudos de Arte Contemporânea (UNL-FCSH) Licenciada em Línguas e Literaturas Modernas - Estudos Portugueses e Pós-Graduada em História da Arte pela UNL-FCSH. Professora de Língua Portuguesa do ensino básico e secundário no Colégio Integrado Monte Maior (Loures). A convite da Cinemateca coordena a edição das obras de crítica cinematográfica de Roberto Nobre (Horizontes de Cinema, o Fundo, Singularidades do Cinema Português e textos dispersos). Desde 2005, é colaboradora da revista Atlântida do Instituto Açoriano de Cultura e da revista Castriana. 